\section{Common mechanism of infection by lentiviruses}

C hemokine receptors are cofactors for infection with HIV-1 (refs 1, 2). HIV-2 and simian immunodeficiency virus (SIV) can infect feline cells expressing human CD4 (ref. 3), suggesting that feline cell-surface molecules can act as co-receptors for HIV infection. Here we demonstrate that the chemokine receptor CXCR4 mediates cell-cell fusion by cell-culture-adapted strains of feline immunodeficiency virus (FIV), indicating that there might be a common mechanism of infection by the primate and feline lentiviruses.

Cell-culture-adapted strains of FIV can infect and fuse with human cells ${ }^{4}$. Moreover, the ability of the FIV envelope glycoprotein (Env) to fuse with human cells is conveyed by a glutamate-to-lysine substitution in the V3 variable loop of its aminoacid sequence ${ }^{5}$, mirroring changes observed in the HIV V3 loop with the switch from a 'non-syncytium-inducing' to a 'syncytiuminducing' phenotype ${ }^{6}$, that is, to a phenotype that induces multinucleated cells. As the V3 loop is a primary determinant of the cell tropism of HIV and FIV, and may determine the nature of the chemokine receptor used by HIV (ref. 7), these data implicate feline chemokine receptors as candidate cellular receptors for FIV.

In the absence of reagents that can recognize feline chemokine receptors, we investigated fusion between persistently infected feline cells (CrFK) and human cells (HeLa). Mixing of FIV-infected CrFK cells with HeLa cells results in cell-cell fusion within 18 to 24 hours. We then screened monoclonal antibodies against cell-surface antigens for their ability to inhibit fusion. Incubation with the anti-human CXCR4 antibody $12 \mathrm{G} 5$ (ref. 8) significantly inhibits fusion at concentrations between 1 and 10 $\mu \mathrm{g} \mathrm{ml}^{-1}$, with maximal inhibition (>90\%)

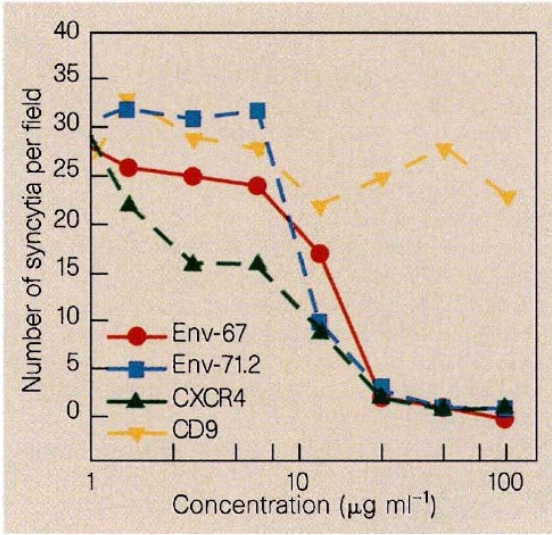

Figure 1 Effect of antibodies on FIV-mediated fusion of HeLa cells. HeLa cells were incubated for $1 \mathrm{~h}$ with either anti-feline CD9 (vpg15), antihuman CXCR4 (12G5), anti-FIV Env (Env-67) or anti-FIV Env (Env-71.2). FIV-producing CrFK cells were then added and incubated for $24 \mathrm{~h}$. The number of syncytia per field was scored using a $\times 12.5$ periplan eyepiece $(6.5 \times 9$ graticule $)$. Syncytia were scored as multinucleated cells containing five or more nuclei per cell.

at concentrations from 25 to $100 \mu \mathrm{g} \mathrm{ml}^{-1}$ (Fig. 1). Fusion is inhibited to a similar degree by the anti-FIV Env antibodies Env-67 and Env-71.2, confirming that the fusion is indeed FIV Env-specific. Incubation of the cells in the presence of a range of antibodies recognizing cell-surface antigens on either CrFK or HeLa cells does not affect fusion, even when they are included at concentrations equivalent to, or greater than, $12 \mathrm{G} 5$.

Similarly, fusion is not inhibited by incubation with a high-titre, neutralizing goat serum against the feline endogenous retrovirus RD114, but is inhibited efficiently by a polyclonal serum from an FIV-infected specific-pathogen-free cat. As the 12G5 antibody does not recognize feline cells expressing the feline homologue of CXCR4 (data not shown), these data indicate that the inhibitory activity might be mediated by binding of the 12G5 antibody to human CXCR4 on the surface of the human cells. Moreover, susceptibility to FIV Env-dependent fusion can be reconstituted by transfection of CXCR4-negative human cells with CXCR4 (B. J. W., L. Picard, M. J. H., J. D. T. \& P. R. Clapham, manuscript in preparation), confirming that CXCR4 is indeed a cofactor for FIV Env-dependent fusion.

Our findings suggest that cell-cultureadapted strains of FIV use the CXC chemokine receptor CXCR4 to infect and fuse with human cells. We believe that this is the first evidence of shared chemokine receptor use between primate and nonprimate lentiviruses. FIV has puzzled AIDS researchers as it causes immunodeficiency with $\mathrm{CD}^{+} \mathrm{T}$-cell depletion but has a broader host range which includes $\mathrm{CD}^{-}$cell types. It seems that the chemokine receptor may be a common link between FIV and the primate lentiviruses and a key determinant of the pathogenesis of AIDS.

Brian J. Willett

Margaret J. Hosie

James C. Neil

Department of Veterinary Pathology,

University of Glasgow,

Glasgow G61 1QH, UK

e-mail:b.willett@vet.gla.ac.uk

Julie D. Turner

James A. Hoxie

Rm 664, Clinical Research Building,

University of Pennsylvania,

415 Curie Boulevard,

Philadelphia, Pennsylvania 19104, USA

\footnotetext{
1. Feng, Y., Broder, C. C., Kennedy, P. E. \& Berger, E. A. Science 272 872-877 (1996).

2. Dragic, T. et al. Nature 381, 667-673 (1996).

3. McKnight, A., Clapham, P. R. \& Weiss, R. A. Virology 201, 8-18 (1994).

4. Pancino, G., Castelot, S. \& Sonigo, P. Virology 206, 796-806 (1995).

5. Verschoor, E. J. J. Virol. 69, 4752-4757 (1995).

6. de Jong, J. J., de Ronde, A., Keulen, W., Tersmette, M. \&

Goudsmit, J. J. Virol. 66, 6777--6780 (1992).

7. Choe, H. et al. Cell 85, 1135-1148 (1996).

8. Endres, M. J. et al. Cell 87, 745-756 (1996).
}

\section{Volcanic iron, $\mathrm{CO}_{2}$, ocean}

\section{productivity and climate}

The results of the IronEx II experiment show that, in the equatorial Pacific Ocean at least, the growth of unicellular marine diatoms can be dramatically increased by the addition of nanomolar quantities of inorganic iron to surface water ${ }^{1-4}$. In common with the Southern Ocean and, to a lesser extent, parts of the northeast Pacific, these waters are termed 'high-nutrient, lowchlorophyll', meaning that the normal nutrients nitrate and phosphate are found in significant quantities at the surface, unused by plankton. Addition of iron leads to uptake of much of these unused nutrients and an associated amount of inorganic carbon. Here I draw attention to further implications of the IronEx results. First, oceanic $\mathrm{pH}$ may increase in response to increased iron supply on a timescale of tens of thousands of years. Second, increased iron flux due to volcanic dust should increase oceanic productivity and hence atmospheric oxygen.

Though their application to the Southern Ocean remains untested, the IronEx results add credence to the suggestion that the ecosystem of the Southern Ocean is iron-limited $^{5,6}$. They also indicate that an increase in the iron supply to that region, such as seems to have occurred during the last glacial period ${ }^{7,8}$, would specifically benefit diatoms there. A general increase in productivity would rapidly (response time of roughly 100 years) tend to decrease atmospheric carbon dioxide ${ }^{9,10}$ because of decreased fugacity of $\mathrm{CO}_{2}$ at the ocean surface. However, the stimulation specifically of diatoms (which fix organic but not calcite carbon) would further reduce atmospheric $\mathrm{CO}_{2}$ by means of a change in the inorganic 